\title{
Histological and electron microprobe studies of mineralisation in aluminium-related osteomalacia
}

\author{
B F Boyce, J Byars, S McWilliams, M Z Mocan, H Y Elder, I T Boyle, B J R Junor
}

\begin{abstract}
Aims To determine a possible mechanism to explain the presence of aluminium lines within fully calcified bone in aluminium-related osteomalacia.

Methods Fifty five bone cases shown by bone biopsy to be aluminium-related osteomalacia were studied. In 38 specimens aluminium lines were identified within calcified bone by means of the Aluminon stain and a characteristic form of patchy mineralisation was seen within thickened osteoid seams. Five representative examples were analysed quantitatively by histomorphometry and electronprobe $X$-ray microanalysis and compared with five cases of vitamin $D$ deficiency-related osteomalacia which also had patchy mineralisation.
\end{abstract}

Results The patchy calcification occupied $40 \pm 8 \%$ (mean \pm SEM) of the osteoid and consisted of small focal deposits ( $<40 \mu \mathrm{m}$ diameter), often ( $52 \%$ ) around osteoid osteocytes (probably an underestimate of the association), and larger areas that extended to the aluminium lines at the underlying mineralisation front. Small and large mineralisation nuclei were seen ultrastructurally in the patchy calcification. Quantitative electronprobe $X$-ray microanalysis showed that calcium concentrations and calcium:phosphorus ratios in the mineralisation nuclei and in the superficial layer of the fully calcified bone of the aluminium-related osteomalacia cases were significantly less than values measured at similar sites in the vitamin D deficiency-related osteomalacia cases. Furthermore, aluminium could not be detected by means of this technique at the mineralisation front or along cement lines in these specimens.

Conclusions Calcification can occur in thickened osteoid seams in osteomalacia. It can begin around osteoid osteocytes as small deposits that enlarge within the osteoid and extend to the underlying mineralisation front or cement line where aluminium lines may become trapped. Complete calcification of osteoid could account for the presence of aluminium lines within fully calcified bone. The Aluminon stain appears to be a more sensitive method for the detection of aluminium in bone than electronprobe $X$ ray microanalysis.
Aluminium can be detected at the interface between osteoid and calcified matrix (the mineralisation front) in bone from some patients with chronic renal failure ${ }^{1-6}$ after exposure to high levels of aluminium in the dialysis water $^{78}$ or following treatment with aluminiumcontaining phosphate-binding drugs. ${ }^{3910} \mathrm{At}$ this site it appears to interfere with mineralisation and thereby cause osteomalacia, although its precise mechanism of toxic action remains obscure. In many biopsy specimens from patients with aluminium-related osteomalacia, however, one or more aluminium lines can also be seen within the calcified bone matrix. ${ }^{2356}$ Thus, despite the presence of aluminium at the mineralisation front, thickened osteoid seams appear to be able to calcify, although the mechanism whereby this calcification takes place remains unexplained.

On review of our bone biopsy specimens from patients with aluminium-related osteomalacia we noted that many had irregularly shaped areas of patchy mineralisation within the thickened osteoid seams as well as aluminium lines within the fully mineralised bone. This form of mineralisation differs from normal mineralisation in that the latter takes place linearly along the interface between osteoid and calcified bone, the mineralisation front. This front can be seen as a thin line with toluidine blue staining or following tetracycline labelling. We studied the patchy mineralisation in detail using light and electron microscopy.

The results are described of our histomorphometric, ultrastructural, and $X$-ray microanalytical study of the patchy mineralisation in bone biopsy specimens from five patients with aluminium-related osteomalacia. On the basis of the light microscopic and ultrastructural findings we propose a mechanism to explain the presence of aluminium lines within calcified bone that is related to healing of the mineralisation defect.

\section{Methods}

We reviewed sections from 55 undecalcified bone biopsy specimens taken over a five year period from 35 renal dialysis patients with biopsy proven aluminium-related osteomalacia (increased extent and thickness of osteoid seams and positive aluminium staining along the interface between the osteoid and the fully calcified bone, the mineralisation front). In 38 of the specimens we observed irregularly shaped areas of patchy mineralisation within the thickened osteoid seams in sections stained 


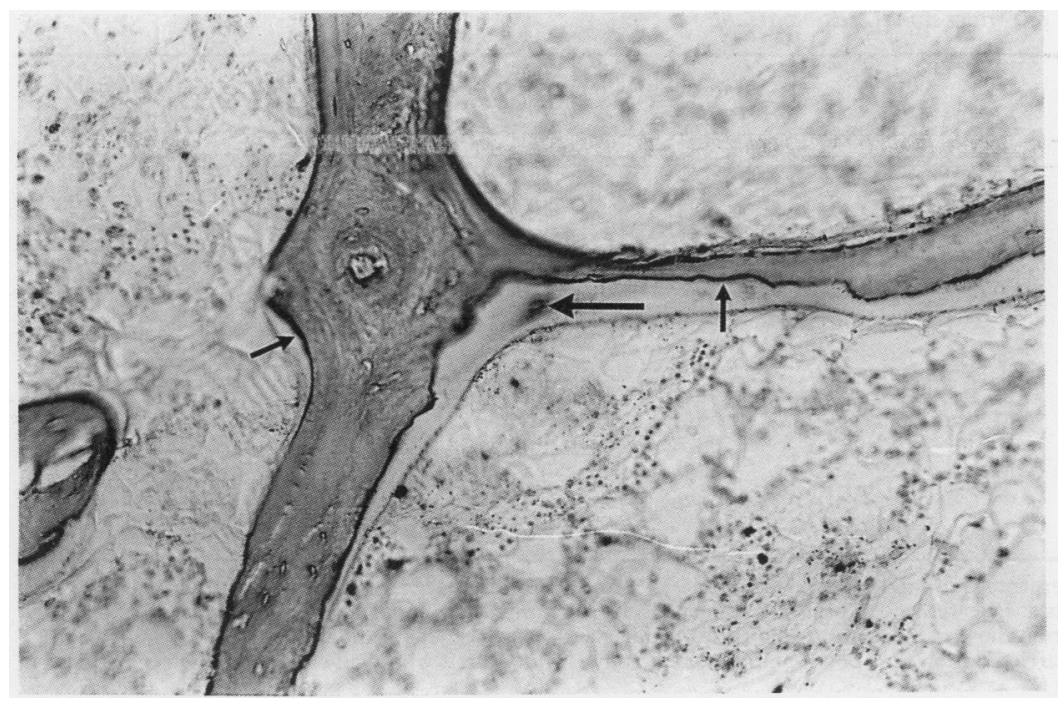

Figure 1 Undecalcified section of bone from case 2 stained for aluminium. Dark staining aluminium lines along the osteoid/calcified bone interface (small arrows); focal calcification (large arrow) within a thickened osteoid seam (Aluminon stain).

with toluidine blue. In the remaining 17 specimens the thickened osteoid seams stained uniformly light blue in toluidine blue stained sections. The appearance of the patchy mineralisation, which was also visible in adjacent sections stained for aluminium (fig 1) and in adjacent sections stained using Von Kossa's stain, varied from small foci to extensive areas of diffuse calcification that was lighter in colour than the underlying fully calcified bone (fig 2 ). There was a variation in the intensity of the staining in these areas of mineralisation from light staining in the small foci to darker staining in the larger areas of diffuse calcification. Some of these darker areas of mineralisation extended to the interface between the osteoid and the fully calcified bone (fig 2) where aluminium was detectable by means of histochemical staining. Furthermore, in all of the 38 biopsy specimens, aluminium lines were also seen within fully calcified bone (fig 3).
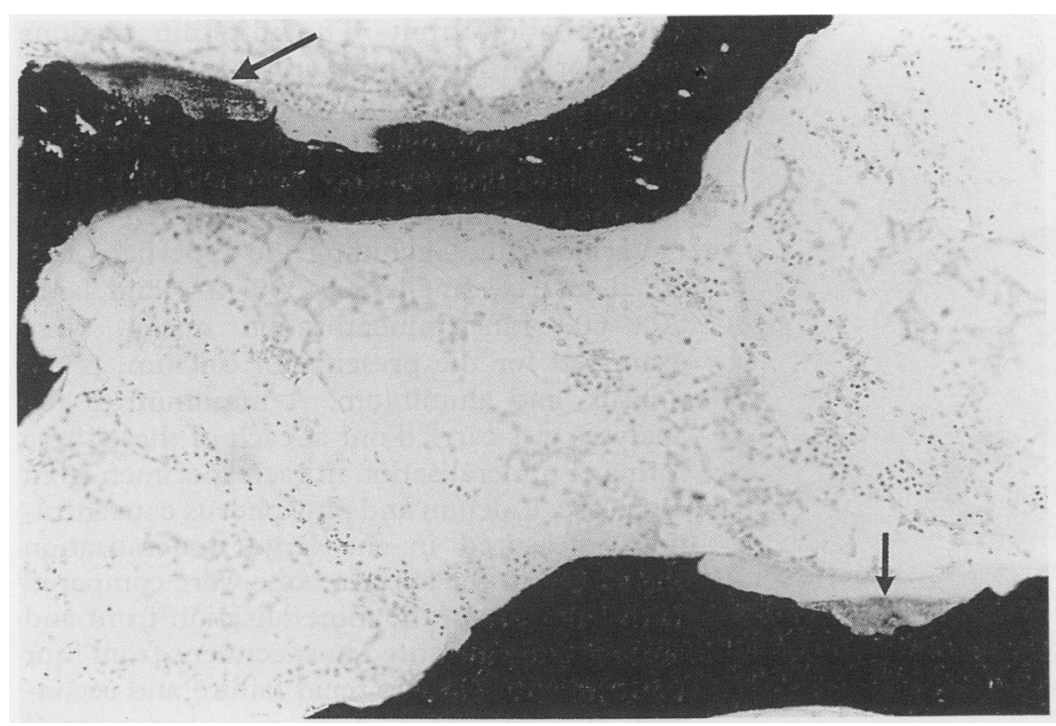

Figure 2 Undecalcified section of bone from case 2. Patchy calcification: light staining (small arrow); dark staining (large arrow) within thickened, pale staining osteoid seams which are focally distributed along the trabeculae (1\% aqueous toluidine blue).
Because detailed electronprobe $X$-ray microanalyis is extremely time consuming and since the histological features of the patchy mineralisation were similar in the 38 specimens, we selected five representative examples of this form of patchy mineralisation from the 38 specimens for detailed histomorphometric and ultrastructural analysis of the mineralisation. We also examined cases of vitamin $\mathrm{D}$ deficiency-related osteomalacia in our bone biopsy files and, for comparison with the above cases, we selected five examples in which areas of similar patchy mineralisation were present.

\section{PATIENTS}

Of the five patients (four men and one woman, aged $20-40$ years) with end-stage chronic renal failure, one (case 1, table 1) had been treated with continuous ambulatory peritoneal dialysis (CAPD) for two years eight months before bone biopsy. The remaining four patients had been treated with regular hemodialysis for between two years eight months and nine years five months before bone biopsy. None of these patients had been exposed to a high level of aluminium in the dialysis water $(>100 \mu \mathrm{g} / \mathrm{l})$ before bone biopsy. The aluminium concentration in the dialysis water was typically $<10 \mu \mathrm{g} / 1$. All five patients had been treated with oral phosphate-binding agents from around the time of their first regular dialysis treatment and this was considered to be their major source of excessive aluminium intake. Their estimated cumulative aluminium hydroxide intake ranged from $2 \cdot 2$ to $9 \cdot 1 \mathrm{~kg}$.

The five patients with vitamin $\mathrm{D}$ deficiencyrelated osteomalacia consisted of two men and three women aged 53-63 years, all of whom had normal renal function. Three had a history of partial gastrectomy for duodenal ulceration. One of these and one other patient had rheumatoid arthritis, and a fifth patient was being treated for congestive cardiac failure and chronic obstructive airways disease and was found to have asymptomatic hypocalcaemia. Only one of these patients (case 7, table 1) had generalised bone pain which had been present for one year. He also had Looser zones seen radiologically but was the only one of these patients to have a normal (adjusted for albumin) serum calcium concentration $(2 \cdot 4$ $\mathrm{mmol} / \mathrm{l})$. The others had hypocalcaemia $(<2 \cdot 05 \mathrm{mmol} / 1$, normal range $2 \cdot 2-2 \cdot 6 \mathrm{mmol} / \mathrm{l})$.

\section{BONE BIOPSIES}

All biopsy specimens ( $8 \mathrm{~mm}$ diameter) were fixed in $10 \%$ neutral phosphate-buffered formalin, dehydrated in graded alcohols and embedded in methyl methacrylate. Serial sections, $8 \mu \mathrm{m}$ thick, were cut on a Jung $\mathrm{K}$ sledge microtome and sections at each of four representative levels were stained with $1 \%$ aqueous toluidine blue and by the Von Kossa method for histomorphometry; $1 \%$ aqueous toluidine blue and $5 \%$ ethylene diamine tetraacetic acid (EDTA) for staining of mineralisation fronts; or Aluminon (aurine tricarboxylic acid) for staining of aluminium. ${ }^{11}$ 
Table 1 Histomorphometry of conventional static variables

\begin{tabular}{|c|c|c|c|c|c|c|c|}
\hline Condition & Patient & Sex & $\begin{array}{l}\text { Osteoid } \\
\text { volume } \\
(O V \mid T V)(\%)\end{array}$ & $\begin{array}{l}\text { Osteoid } \\
\text { surface } \\
\text { (OS/BS) (\%) }\end{array}$ & $\begin{array}{l}\text { Mineralising } \\
\text { fronts } \\
(M F / O S)(\%)\end{array}$ & $M N L$ & $\begin{array}{l}\text { Aluminium } \\
\text { staining (\% } \\
\text { osteoid surface) }\end{array}$ \\
\hline $\begin{array}{l}\text { Aluminium-related } \\
\text { osteomalacia }\end{array}$ & $\begin{array}{l}1 \\
2 \\
3 \\
4 \\
5\end{array}$ & $\begin{array}{l}\mathbf{F} \\
\mathbf{M} \\
\mathbf{M} \\
\mathbf{M} \\
\mathbf{M}\end{array}$ & $\begin{array}{l}2.5 \\
2 \cdot 3 \\
1 \cdot 4 \\
5 \cdot 1 \\
6.5\end{array}$ & $\begin{array}{l}52 \cdot 1 \\
64 \cdot 4 \\
63 \cdot 7 \\
87 \cdot 3 \\
66 \cdot 8\end{array}$ & $\begin{array}{r}1 \cdot 6 \\
9 \cdot 2 \\
3 \cdot 0 \\
13 \cdot 3 \\
19 \cdot 1\end{array}$ & $\begin{array}{r}8 \\
9 \\
7 \\
10 \\
9\end{array}$ & $\begin{array}{l}94 \cdot 3 \\
84 \cdot 3 \\
77 \cdot 4 \\
75 \cdot 4 \\
89 \cdot 6\end{array}$ \\
\hline Mean (SEM) & & & $3.5(1.0)$ & $66.9(5 \cdot 7)$ & $9 \cdot 2(3 \cdot 2)$ & $8.6(0.5)$ & $84 \cdot 2(3 \cdot 6)$ \\
\hline $\begin{array}{l}\text { Vitamin D-related } \\
\text { osteomalacia }\end{array}$ & $\begin{array}{r}6 \\
7 \\
8 \\
9 \\
10\end{array}$ & $\begin{array}{l}\mathrm{F} \\
\mathrm{F} \\
\mathrm{M} \\
\mathrm{F} \\
\mathrm{M}\end{array}$ & $\begin{array}{l}13 \cdot 8 \\
12.9 \\
29 \cdot 4 \\
12 \cdot 2 \\
17.9\end{array}$ & $\begin{array}{l}97 \cdot 9 \\
98 \cdot 2 \\
95 \cdot 2 \\
88 \cdot 7 \\
99 \cdot 8\end{array}$ & $\begin{array}{r}12 \cdot 1 \\
8 \cdot 0 \\
16 \cdot 2 \\
22.5 \\
3 \cdot 5\end{array}$ & $\begin{array}{l}15 \\
13 \\
23 \\
15 \\
18\end{array}$ & $\begin{array}{l}0 \\
0 \\
0 \\
0 \\
0\end{array}$ \\
\hline $\begin{array}{l}\text { Mean (SEM) } \\
\text { Normal range }\end{array}$ & & & $\begin{array}{l}17 \cdot 2^{\star}(3 \cdot 2) \\
<0 \cdot 28\end{array}$ & $\begin{aligned} & 95.9^{\star}(1.9) \\
< & 24\end{aligned}$ & $\begin{array}{l}12.5(3.3) \\
>\end{array}$ & $\begin{array}{l}16 \cdot 8^{\star}(1 \cdot 7) \\
\leqslant 4\end{array}$ & 0 \\
\hline
\end{tabular}

OV/TV, Osteoid volume as a percentage of total cancellous volume; OS/BS, Osteoid surface as a percentage of bone surface; MF/ $\mathrm{OS}$, extent of mineralising fronts as a percentage of osteoid surface; MNL, Maximum number of birefringent lamellae of osteoid. *Values significantly different from those in aluminium-related osteomalacia cases. $p<0.005$, Student's $t$ test.

†Derived from measurements carried out on iliac bone samples taken from 21 individuals who died suddenly with no evidence of metabolic bone disease.

\section{HISTOMORPHOMETRY}

The following conventional static variables were measured by either point counting or line intersect measurement with a Zeiss II eyepiece graticule or by image analysis using a digitising tablet and cursor: osteoid volume (OV/TV) as a percentage of total cancellous space, osteoid surface $(\mathrm{OB} / \mathrm{BS})$ as a percentage of trabecular surface, maximum number of lamellae (MNL) of osteoid visualised under polarised light, the extent of mineralising surface (MS/BS) and of positive aluminium staining along the osteoid/ calcified bone interface to give an indication of the severity of osteomalacia.

The percentage of osteoid undergoing patchy mineralisation was measured by point counting and was subdivided according to whether mineralisation was focal (occurring in small, discreet aggregates $<40 \mu \mathrm{m}$ in diameter) or diffuse, (occurring as confluent bands $>40$ $\mu \mathrm{m}$ in diameter) within osteoid seams. The areas of diffuse mineralisation in each of the toluidine blue-stained sections were subdivided according to whether staining was light or dark (fig 2). The dark areas were not stained

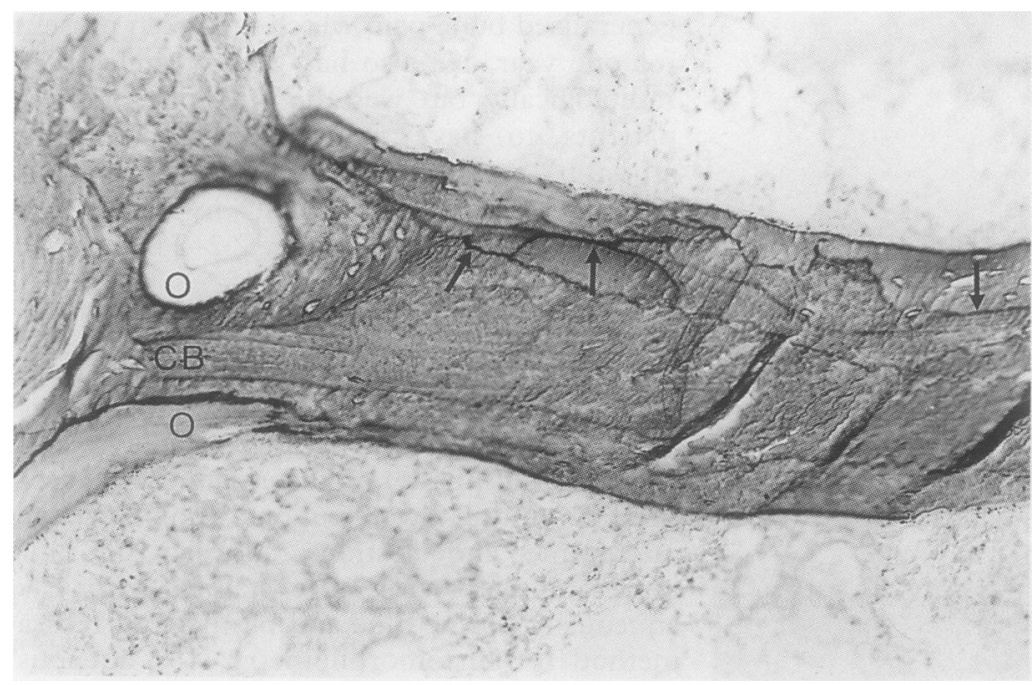

Figure 3 Undecalcified section of bone from case 4 with aluminium-related osteomalacia stained for aluminium. A dark staining aluminium line is present between thickened osteoid seam $(O)$ and the underlying calcified bone $(C B)$. Numerous aluminium lines are also present within the calcified bone (arrows). (Aluminon stain). as heavily or as uniformly as the underlying fully calcified bone. The number of sites of focal calcification ( $<40 \mu \mathrm{m}$ diameter) was counted in three Von Kossa-stained non-consecutive step sections since their outer edges were delineated most clearly with this staining method. Those foci in which an osteoid osteocyte could be visualised (fig 4) were expressed as a percentage of the total number of small foci in each case.

\section{ELECTRON PROBE X-RAY MICROANALYSIS}

This is an established technique used for the localisation and measurement of the concentration of elements within tissue at the ultrastructural level. ${ }^{12}$

Ultrathin sections (150 nm) were prepared from the undecalcified, methyl methacrylateembedded specimens from which the sections for morphometry had already been cut using a technique described previously. ${ }^{1}$ Small blocks $(3 \times 3 \mathrm{~mm})$ were cut from the sectioned faces of each specimen at sites where focal or diffuse mineralisation of the osteoid had been detected in the toluidine blue-stained sections and where aluminium was seen at the underlying mineralisation front. The ultrathin sections were cut through these areas of patchy calcification on a dry diamond knife in an LKB IV ultramicrotome, placed in the centre of formvar support film on copper single hole mounts and then carbon coated.

Various sites, including the superficial calcified matrix, small (200-300 $\mathrm{nm})$ and large (300-600 nm) mineralisation nuclei, were examined for the presence of calcium, phosphorus, and aluminium. A minimum of ten analyses was carried out at each of these three forms of mineralisation in each specimen from each case. Calcium and phosphorus concentrations measured in the large mineralisation nuclei and in the surface bone were compared with values from the mineralisation front and surface bone measured in specimens from four patients with chronic renal failure and secondary hyperparathyroidism who had normal mineralisation and negative aluminium staining. In addition, in the aluminium positive specimens the calcified bone within the 
Table 2 Histomorphometry of patchy calcification

\begin{tabular}{|c|c|c|c|c|c|c|c|}
\hline \multirow[b]{3}{*}{ Condition } & \multirow[b]{3}{*}{$\begin{array}{l}\text { Case } \\
\text { No }\end{array}$} & \multirow{3}{*}{$\begin{array}{l}P C / T V \\
\text { (\% total } \\
\text { (volume) }\end{array}$} & \multirow{3}{*}{$\begin{array}{l}P C / O V \\
\text { (\% osteoid } \\
\text { volume) }\end{array}$} & \multicolumn{3}{|c|}{ (\% of total patchy calcification) } & \multirow{3}{*}{$\begin{array}{l}\text { Periosteocytic } \\
\text { staining } \% \text { foca } \\
\text { calcification }\end{array}$} \\
\hline & & & & \multirow[b]{2}{*}{ Focal } & \multicolumn{2}{|l|}{ Diffuse } & \\
\hline & & & & & $\begin{array}{l}\text { Light } \\
\text { staining }\end{array}$ & $\begin{array}{l}\text { Dark } \\
\text { staining }\end{array}$ & \\
\hline $\begin{array}{l}\text { Aluminium-related } \\
\text { osteomalacia }\end{array}$ & $\begin{array}{l}1 \\
2 \\
3 \\
4 \\
5\end{array}$ & $\begin{array}{l}0.6 \\
1.6 \\
0 \cdot 6 \\
1.9 \\
3.0\end{array}$ & $\begin{array}{l}22 \cdot 4 \\
68 \cdot 9 \\
40 \cdot 6 \\
37 \cdot 1 \\
46 \cdot 5\end{array}$ & $\begin{array}{r}20 \cdot 0 \\
2 \cdot 1 \\
10 \cdot 5 \\
1 \cdot 3 \\
1.8\end{array}$ & $\begin{array}{l}68 \cdot 9 \\
71 \cdot 9 \\
73 \cdot 1 \\
76 \cdot 8 \\
77 \cdot 6\end{array}$ & $\begin{array}{l}11 \cdot 1 \\
26 \cdot 0 \\
16.4 \\
21 \cdot 9 \\
20.6\end{array}$ & $\begin{array}{l}50 \cdot 0 \\
71 \cdot 4 \\
58 \cdot 2 \\
41 \cdot 7 \\
40 \cdot 0\end{array}$ \\
\hline Mean (SEM) & & $1.5(0.5)$ & $43 \cdot 1(7 \cdot 6)$ & $7 \cdot 1(3 \cdot 6)$ & $73.6(1.6)$ & $19 \cdot 2(2 \cdot 5)$ & $52 \cdot 3(5 \cdot 8)$ \\
\hline $\begin{array}{l}\text { Vitamin D-related } \\
\text { osteomalacia }\end{array}$ & $\begin{array}{r}6 \\
7 \\
8 \\
9 \\
10\end{array}$ & $\begin{array}{r}3.3 \\
12.9 \\
19.5 \\
5.0 \\
3.0\end{array}$ & $\begin{array}{l}24 \cdot 2 \\
45 \cdot 2 \\
66 \cdot 2 \\
40 \cdot 6 \\
16 \cdot 6\end{array}$ & $\begin{array}{l}2 \cdot 6 \\
0 \cdot 8 \\
0 \cdot 7 \\
4 \cdot 7 \\
3 \cdot 7\end{array}$ & $\begin{array}{l}66 \cdot 2 \\
77 \cdot 5 \\
75 \cdot 7 \\
72 \cdot 9 \\
64 \cdot 9\end{array}$ & $\begin{array}{l}31 \cdot 1 \\
21 \cdot 7 \\
23 \cdot 5 \\
22 \cdot 4 \\
31 \cdot 3\end{array}$ & $\begin{array}{l}35 \cdot 5 \\
25 \cdot 6 \\
34 \cdot 6 \\
43 \cdot 2 \\
42 \cdot 1\end{array}$ \\
\hline Mean (SEM) & & $8 \cdot 7 \star(3 \cdot 2)$ & $38.5(8.6)$ & $2.4(0.9)$ & $71 \cdot 6(2 \cdot 6)$ & $26 \cdot 0(2 \cdot 1)$ & $36 \cdot 2^{\star}(3 \cdot 1)$ \\
\hline
\end{tabular}

PC/TV, patchy calcification as a percentage of total cancellous space; PC/OV, patchy calcification as percentage of osteoid volume. ${ }^{*} \mathrm{p}<0.05$.

trabeculae was probed systematically for aluminium at sites corresponding to the location of the aluminium lines in the histological sections (fig 2).

The microanalysis was carried out in a transmission electron microscope (JEOL JEM $100 \mathrm{C}$ ) with a $30 \mathrm{~mm}^{2} \mathrm{KEVEX}$ energy dispersive detector and an attached Link Systems 290 microanalysis system and the concentrations of calcium and phosphorus were calculated according to the method of Hall. ${ }^{13}$ The system had been modified for accurate ultrastructural analysis of hard tissues. ${ }^{14}$ The analysis conditions were $80 \mathrm{kV}$ accelerating voltage, $0.3 \mathrm{nA}$ probe current focussed to $\approx 200 \mathrm{~nm}$ spot size and 60 seconds analysis, live time.

\section{Results}

BONE HISTOLOGY AND HISTOMORPHOMETRY

Mineralisation

Individual values for osteoid volume, osteoid surface, maximum number of osteoid lamellae, extent of mineralising fronts and aluminium staining for all specimens are listed in table 1. Osteoid seams were increased in extent (OS/BS

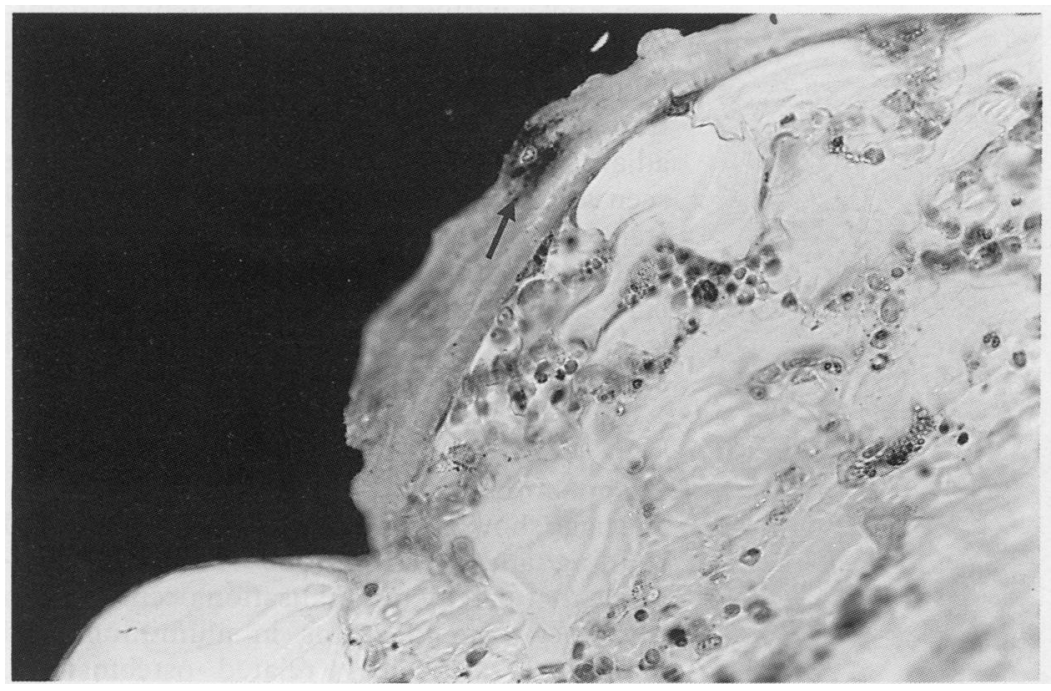

Figure 4 Undecalcified section of bone from case 1. A small area of focal calcification (arrow) is present around an osteoid osteocyte within a thickened osteoid seam (Von Kossa).
$>52 \%)$ and thickness (MNL $>7$ ), osteoid volumes were increased $(\mathrm{OV} / \mathrm{TV}>1.4 \%)$, and the extent of mineralising fronts was decreased $(<23 \%)$ in all specimens, indicating osteomalacia. Aluminium was detectable along more than $75 \%$ of the osteoid/bone interface (fig 1) and was also present along cement lines within fully calcified bone in the specimens from the renal dialysis patients (fig 3 ). The thickened osteoid seams had a focal distribution along trabecular surfaces typical of some cases of aluminium-related osteomalacia (fig 2) rather than the more extensive pattern seen typically in vitamin $\mathrm{D}$ deficiency-related osteomalacia. This accounts for the significantly lower values for osteoid volumes and surfaces in the aluminium-related osteomalacia specimens (table 1 ). Figure 2 also shows typical examples of the pale and dark staining patchy mineralisation in a case of aluminium-related osteomalacia. Aluminium was not detectable histochemically in any of the cases of vitamin D deficiency-related osteomalacia.

Values for the histomorphometry of the patchy calcification in the renal patients and in the patients with vitamin $\mathrm{D}$ deficiency-related osteomalacia are listed in table 2 . The mean absolute volume of the patchy calcification (PC/TV) in the aluminium-related osteomalacia cases $(1.5 \pm 0.5 \%)$ was significantly lower than in the cases of vitamin D deficiencyrelated osteomalacia $(8 \cdot 7 \pm 3 \cdot 2 \%)$, reflecting the lower absolute osteoid volume. However, there was no significant difference between mean values in the two groups for the percentage of the calcification that was focal, light, or dark staining. Although, as expected among the four levels, there was some variation in the values for the three types of patchy calcification in each case (data not shown), the pattern of staining at each level seen with toluidine blue, toluidine blue plus EDTA and Von Kossa was consistent and reproducible.

Osteocytes were seen in the middle of more than half $(52 \pm 6 \%)$ of the microscopic discrete foci of calcification in the cases of aluminiumrelated osteomalacia (fig 4) and this was significantly greater than in the cases of vitamin D deficiency-related osteomalacia $(36 \pm 3 \%)$. 


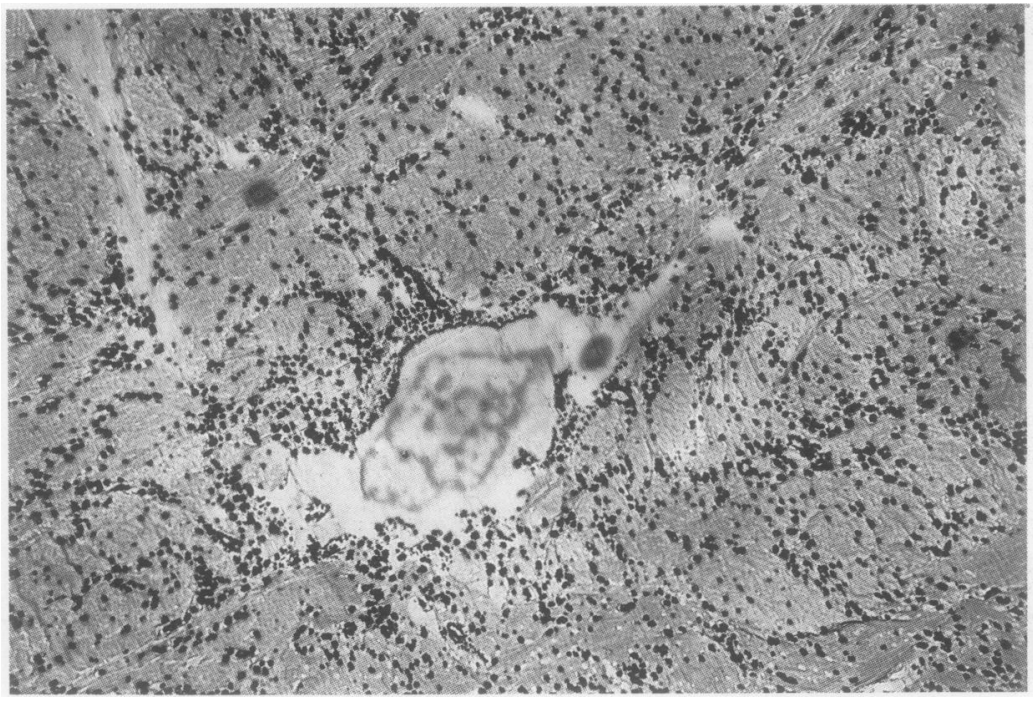

Figure 5 Electron micrograph of undecalcified section of bone from case 2. Numerous electron-dense mineralisation nuclei are present around an osteoid osteocyte. (Unstained ultrathin section).

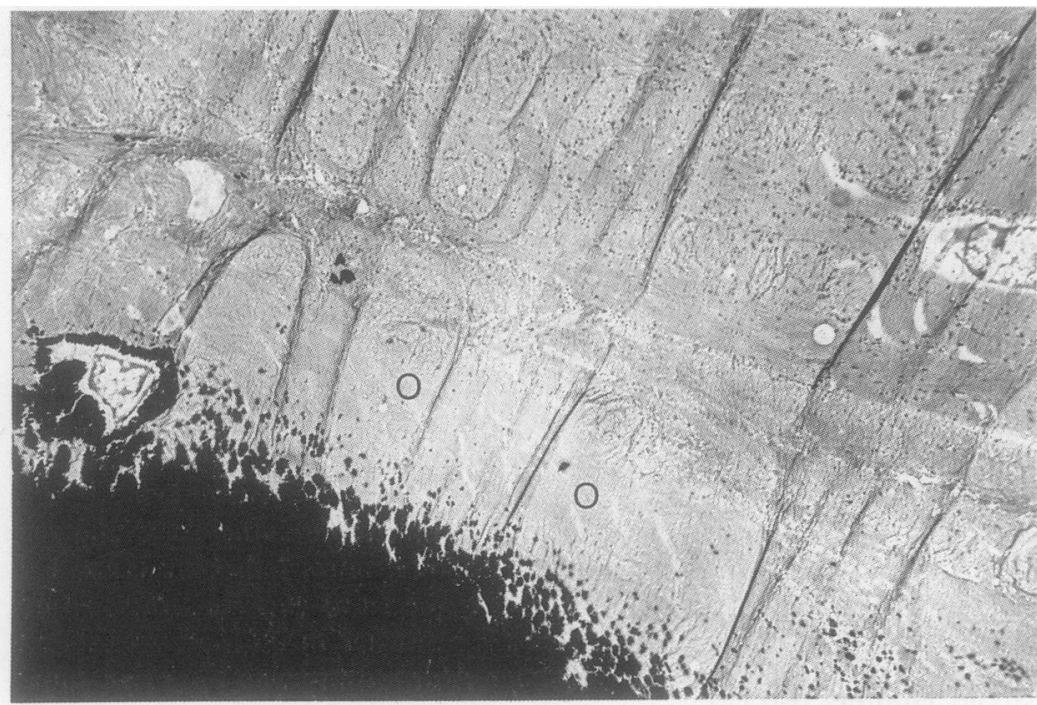

Figure 6 Electron micrograph of undecalcified section of bone from case 2. Fully calcified bone (black) is present at bottom left. Mineralisation nuclei are widely dispersed within osteoid at the top of the micrograph and an area.with few mineralisation nuclei $(O)$ is present between these and the underlying mineralisation front. (Unstained ultrathin section).

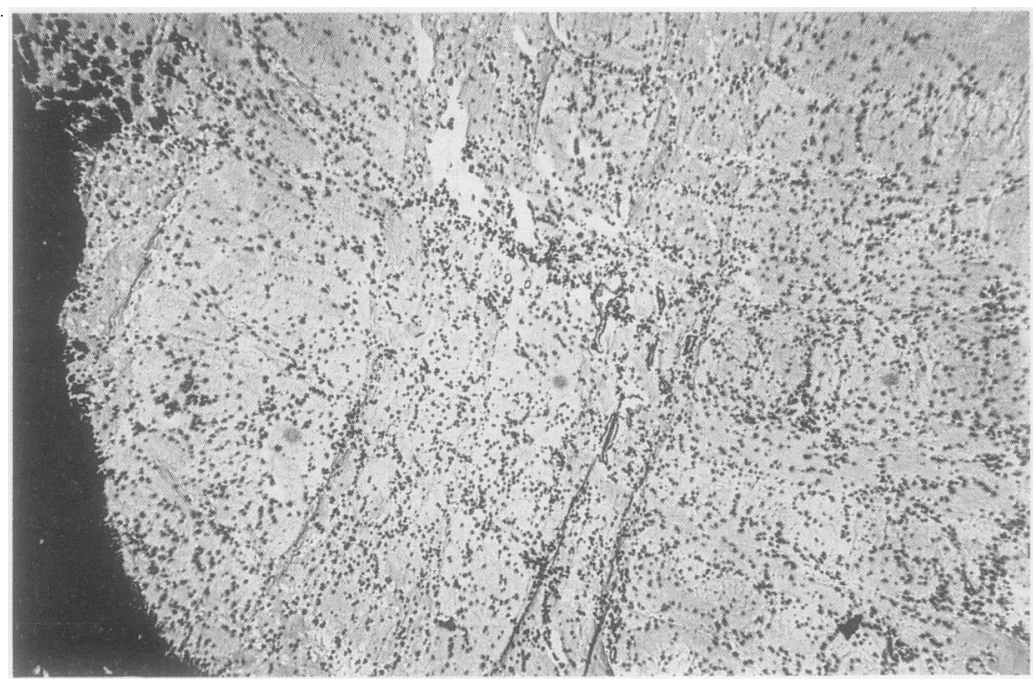

Figure 7 Electron micrograph of undecalcified section of bone from case 2. Mineralisation nuclei are present extensively within osteoid and extend to the mineralisation front. (Unstained ultrathin section).

\section{ELECTRON PROBE X-RAY MICROANALYSIS}

Ultrastructural examination of the ultrathin sections cut from each biopsy specimen from both groups of patients showed a widespread distribution of discrete, electron-opaque structures within the thickened osteoid. At some sites, particularly in the aluminium-positive renal cases, their distribution was heaviest around osteoid osteocytes (fig 5) corresponding to the periosteocytic calcification seen in the histological sections. A relatively clear zone was seen between these mineralisation nuclei and the mineralisation nuclei at the osteoid/ bone interface (fig 6). At other sites a more widespread distribution was present within osteoid (fig 7). The mineralisation nuclei within these areas of diffuse calcification ranged in size from $\approx 100-600 \mathrm{~nm}$ in diameter.

Mean calcium concentrations (fig 8) and mean $\mathrm{Ca}^{2+}: \mathrm{P}^{-}$mass ratios (fig 9) in the large mineralisation nuclei $(300-600 \mathrm{~nm})$ and surface bone in the aluminium-related osteomalacia specimens were significantly lower than values in corresponding sites in the vitamin D deficiency-related osteomalacia specimens. Calcium concentrations and $\mathrm{Ca}^{2+}: \mathbf{P}^{-}$ratios in the large $(300-600 \mathrm{~nm})$ and small $(<300 \mathrm{~nm})$ mineralisation nuclei in the aluminium-related osteomalacia samples were significantly lower than values in the surface bone of the vitamin $D$ deficiency-related osteomalacia samples. In addition, the calcium concentrations and $\mathrm{Ca}^{2+}: \mathrm{P}^{-}$ratios in the large mineralisation nuclei in the aluminium-related osteomalacia specimens were significantly lower than the values in the superficial calcified bone in the four secondary hyperparathyroidism specimens $\left(\mathrm{Ca}^{2}+282 \pm 15 \mathrm{mg} / \mathrm{g}, \mathrm{p}<0.02\right.$; $\mathrm{Ca}^{2+}: \mathrm{P}^{-} 1.91 \pm 0.01, \mathrm{p}<0.001$ ) (figs 8 and 9). However, values for phosphorus concentrations measured in the large mineralisation nuclei and in the superficial calcified bone in the aluminium-related osteomalacia specimens did not differ significantly from those in the vitamin $\mathrm{D}$ deficiency-related osteomalacia or secondary hyperparathyroidism specimens (data not shown).

Aluminium was not detected in mineralisation nuclei within the areas of patchy mineralisation and, surprisingly, was rarely detectable in sites probed within the superficial layer of the calcified bone or in the immediately adjacent mineralisation nuclei despite being seen at these sites by means of histochemical stain. Furthermore, aluminium was not detectable deep within the fully calcified bone at sites corresponding to the location of positively stained aluminium lines in the histological sections.

\section{Discussion}

We have shown by means of both histochemical staining and electronprobe $X$-ray microanalysis that patchy mineralisation occurs within thickened osteoid seams in aluminium and vitamin $\mathrm{D}$ deficiency related osteomalacia. These irregularly shaped areas of mineralisation occupied up to $69 \%$ of the volume of the osteoid and ranged in size from small foci $(<40$ 
Figure 8 Relative calcium concentrations (mean $+S E M)$ measured by means of electronprobe $X$-ray microanalysis in mineralisation nuclei and in the surface layer of the fully calcified bone of the osteoid/calcified bone interface. $\square$, Aluminiumrelated osteomalacia; DD, vitamin D deficiency-related osteomalacia samples. Student's $t$ test for nonpaired samples. ${ }^{\star} p<0.01 ;{ }^{\star \star} p<0.005$.

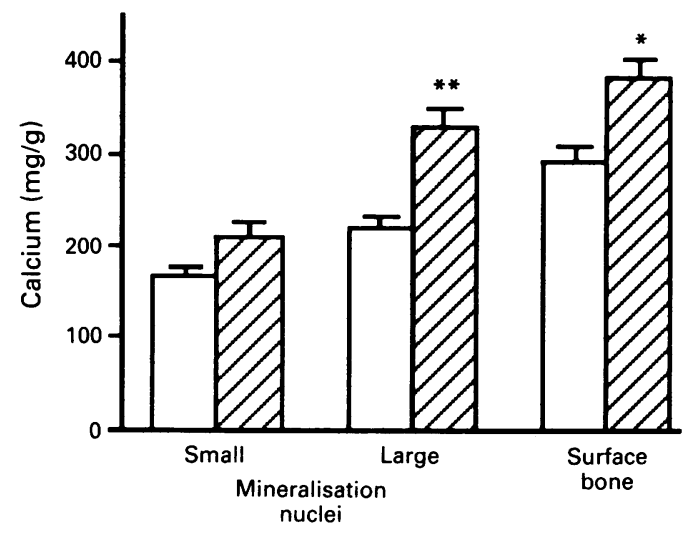

$\mu$ m diameter) to larger areas of diffuse calcification that often extended to the underlying osteoid/calcified bone interface. A single osteocyte was often seen in the middle of the small foci (in 52 and $36 \%$ of the foci in the aluminium and vitamin $\mathrm{D}$ cases, respectively) suggesting that, at least in the aluminiumrelated osteomalacia cases, mineralisation could have begun around these cells. These percentages will provide an underestimate of the presence of osteocytes in small mineralisation foci since the average osteocyte diameter is close to the section thickness $(8 \mu \mathrm{m})$ and thus is much smaller than the maximum diameter of the foci $(40 \mu \mathrm{m})$.

On the basis of these findings, we conclude that in both of these conditions large areas of patchy mineralisation have developed within thickened osteoid seams through a process which could have begun around osteoid osteocytes as small foci that enlarged and merged with one another as mineralisation progressed. The extension of the mineralisation to the aluminium lines at the osteoid/ calcified bone interface and its subsequent complete mineralisation could account for the presence of aluminium lines within fully calcified bone, as observed previously.

We have observed patchy mineralisation within thickened osteoid seams in other forms of osteomalacia, for example, in etidronatetreated patients with Paget's disease (unpublished results). On review of these cases we noted diffuse tetracycline uptake within the areas of patchy mineralisation, a finding similar to that reported by Charhon et al in a case of aluminium related osteomalacia. ${ }^{15}$ Both etidronate and aluminium have a toxic action on mineralisa-

Figure 9 Calcium: phosphorus mass ratios (mean $\pm S E M)$ measured by means of electronprobe $X$-ray microanalysis in mineralisation nuclei and in the surface layer of the in the surface layer of the osteoid/calcified bone interface. $\square$, Aluminiumrelated osteomalacia; D2, vitamin $D$ deficiency-related osteomalacia. ${ }^{\star} p<0.01$ $\star \star \star p<0.001$. Student's test for non-paired samples. tion in contrast to the effects of a deficiency of vitamin $\mathrm{D}$ and both are often associated with focal, rather than diffusely distributed, thickened osteoid seams. This toxic action on bone turnover is likely to account for the significantly lower values for osteoid volumes and surfaces in the aluminium-related osteomalacia cases (table 1). We believe that the patchy mineralisation represents a form of healing of the defect that begins to take place presumably after the local concentration of the toxin in bone has fallen below an, as yet undefined, inhibitory threshold value.

Bordier described diffuse mineralisation within thickened osteoid seams in patients with vitamin $\mathrm{D}$ deficiency-related osteomalacia and suggested that it occurred in response to treatment with phosphate rather than with vitamin $\mathrm{D}$ and calcium. ${ }^{16}$ The raised serum phosphate concentrations in the renal dialysis patients in our study (data not included) and the hyperphosphataemia that often accompanies etidronate-related osteomalacia in Paget's disease $^{1718}$ could support this suggestion. However, it is not supported by the finding of normal or low serum phosphate concentrations in the patients with vitamin D deficiencyrelated osteomalacia in our study who did not receive treatment with phosphate. Thus, the explanation of the occurrence of patchy mineralisation remains obscure.

Ultrastructural examination of the areas of patchy mineralisation confirmed that calcification was less dense than the underlying fully calcified bone and that the appearances corresponded to those seen histologically. In addition to confirming the presence of calcium in the areas of patchy mineralisation, we measured the concentration of calcium and phosphorus in the fully mineralised bone and in mineralisation nuclei within osteoid. There were two main findings. Firstly, in the aluminium-related osteomalacia specimens calcium concentrations and calcium:phosphorus ratios in the superficial calcified bone and in the large mineralisation nuclei were significantly lower than the corresponding values in the vitamin $\mathrm{D}$ deficiency-related osteomalacia specimens. Secondly, the calcium concentrations and calcium:phosphorus ratios in the large mineralisation nuclei in the aluminium-related osteomalacia specimens were significantly lower than values in the superficial calcified bone in the vitamin $D$ deficiency-related osteomalacia specimens and secondary hyperparathyroidism specimens. The low calcium: phosphorus ratios in these sites were due to low calcium concentrations since there was no significant difference in phosphorus concentrations between the aluminium and vitamin $D$ deficiency-related cases. The explanation for the low calcium concentrations in the superficial calcified bone and in the mineralisation nuclei in the aluminium related osteomalacia cases is not clear from our studies.

We used the electron microprobe to attempt to detect aluminium at the mineralisation front beneath areas of patchy mineralisation and within fully calcified bone, two sites where it was visible with the Aluminon stain. We did 
not see aluminium peaks on most of the spectra at these sites and the aluminium concentrations did not rise above background, presumably because they were below the limit of detection of this system (approximately one part per thousand) which thus appears to be less sensitive than the Aluminon stain. In contrast, in our previous studies of aluminium-related osteomalacia, we were able to detect aluminium by means of both histochemical stain and the electron microprobe at the osteoid/calcified bone interface. ${ }^{13}$ However, in those 21 cases patchy calcification was not present within the thickened osteoid seams above the aluminium deposits.

We do not know why the concentration of aluminium in the present cases is below the limit of detection of the electron microprobe. One possible explanation is that the aluminium gradually leaches out of bone with time as has been observed histochemically on unremodelled bone. ${ }^{19} \mathrm{~A}$ gradual reduction in the aluminium concentration in bone could permit the return of mineralisation, albeit patchy, as in our cases, although the mechanism of reduction is not clear. Rapid removal of aluminium from bone can occur during treatment with desferrioxamine but this appears to be followed by the return of normal bone mineralisation along calcified bone/osteoid interfaces ${ }^{2021}$ rather than patchy mineralisation within the thickened osteoid seams. In these studies, histochemical staining rather than electron microprobe analysis was used to detect aluminium. We are unaware of other studies which have compared the sensitivity of $X$-ray microanalysis with histochemical stains for aluminium in specimens showing healing of the mineralisation defect. However, Denton et al have shown previously than in cases of aluminium-related osteomalacia another stain for aluminium, solochrome asurine, is more sensitive than wavelength dispersive $X$-ray microanalysis, a technique that is more sensitive than the energy dispersive $X$-ray microanalysis that we used. ${ }^{22}$

This work was supported by a grant from the Scottish Hospital Endowments Research Trust. We are grateful to Isabel Main and Olga German for their expert secretarial help.
1 Boyce BF, Elder HY, Fell GS, et al. Quantitation and localization of aluminium in human cancellous bone in renal osteodystrophy. Scanning Electron Microsc 1981; 3:329-37.

2 Cournot-Witmer G, Zingraff J, Plachot JJ, et al. Aluminum localization in bone from hemodialyzed patients: relationship to matrix mineralization. Kidney Int 1981;20:375-85.

3 Boyce BF, Fell GS, Elder HY, et al. Hypercalcemic osteomalacia due to aluminium toxicity. Lancet 1982; ii: $1009-13$.

4 Ott SM, Maloney NA, Coburn JW, Alfrey AC, Sherrard DJ. The prevalence of bone aluminum deposition in renal osteodystrophy and its relation to the response to calcitriol therapy. N Engl J Med 1982;307:709-13.

5 Maloney NA, Ott SM, Alfrey A, Miller NL, Coburn JW, Sherrard DJ. Histologic quantitation of aluminum in iliac bone from patients with renal failure. J Lab Clin Med 1982;99:206-16.

6 Charhon SA, Chavassieux PM, Chapuy MC, Boivin GY, Meunier PJ. Low rate of bone formation with or without histologic appearance of osteomalacia in patients with histologic appearance of osteomalacia in patients with
aluminum intoxication. J Lab Clin Med 1985;106:123-31.

7 Platts MM, Goode GC, Hislop JS. Composition of the domestic water supply and the incidence of fractures and domestic water supply and the incidence of fractures and
encephalopathy in patients on home dialysis. $\mathrm{Br} \mathrm{Med} \mathrm{J}$ encephalopathy

8 Elliot HL, Dryburgh F, Fell GS, Sabat S, MacDougall AI Aluminium toxicity during regular haemodialysis. $\mathrm{Br} \mathrm{Med}$ $J$ 1978; i: 1101-3.

9 Felsenfeld AJ, Gutman RA, Llach F, Harrelson JM. Osteomalacia in chronic renal failure: A syndrome previously reported only with maintenance dialysis. $A m$ Nephrol 1982;2:147-54.

10 Andreoli SP, Bergstein JM, Sherrard DJ. Aluminum intoxication from aluminum-containing phosphate binders in ication from aluminum-containing phosphate binders in
children with azotemia not undergoing hemodialysis. children with azotemia not under

11 Buchanan MRC, Ihle BU, Dunn CM. Haemodialysisrelated osteomalacia: a staining method to demonstrate aluminium J Clin Pathol 1981;34:1352-4.

12 Chandler JA. $X$-ray microanalysis in the electron microscope. Amsterdam: North Holland, 1977.

13 Hall HA. The microprobe assay of chemical elements. Optical techniques. In: Oster G, ed. Physical techniques in biological research. 2nd Edition. New York: Academic Press, 1975:157-275.

14 Nicholson WAP, Gray CC, Chapman JN, Robertson BW. Optimising thin film X-ray spectra for quantitative analysis. J Microsc 1982;125:25-40.

15 Charhon SA, Chavassieux PM, Chapuy MC, Traeger J, Meunier PJ. High bone turnover associated with an Meunier PJ. High bone turnover associated with an
aluminium-induced impairment of bone formation. Bone aluminium-induce

16 Bordier PJ, Tun-Chot S, Martin J, Queille ML, Hioco D. Mineralisation du tissue ostéoide chez l'ostéomalacique induité par surcharge phosphorée ou par la vitamine $D_{3}$. In: Hioco D, ed. Phosphate et metabolisme phosphocalcique. Paris: Editions Sandoz, 1971:79.

17 Boyce BF, Smith L, Fogelman I, Johnston E, Ralston S, Boyle IT. Focal osteomalacia due to low-dose diphosphonate therapy in Paget's disease. Lancet 1984; i:821-4.

18 Ralson SH Boc BF, Cowan RA. Lal. The effect of $1 \alpha-$ hydroxyvitamin $\mathrm{DF}$, Cowan RA, et al. The effect of $1 \alpha-$ hydroxyvitamin $D_{3}$ on the mineralization defect in disodium etidronate-treated Paget's disease-a double-
blind randomized clinical study. J Bone Min Res 1987;2: 5-11.

19 Freemont AJ. Cellular and subcellular localization of aluminum: Histochemistry. In: De Broe ME, Coburn JW, eds. Aluminum and renal failure. The Netherlands Kluwer, 1990:155-66.

20 Ott SM, Andress DC, Nebeker HG, et al. Changes in bone histology after treatment with deferoxamine. Kidney Int 1986;29,S18:108-13.

21 Charhon SA, Chavassieux P, Boivin G, et al. Deferoxamineinduced bone changes in haemodialysis patients-a histomorphometric study. Clin Sci 1987;73:227-34.

22 Denton J, Freemont AJ, Ball J. Detection and distribution of aluminium in bone. J Clin Pathol 1984;37:136-42. 